\title{
POLYMERASE CHAIN REACTION (PCR) - AN EFFICIENT TOOL FOR DIAGNOSIS OF INFLUENZA AND ACUTE RESPIRATORY ILLNESSES DURING INFLUENZA SEASON
}

\author{
Lucia Mad'arová ${ }^{1}$, Soňa Feiková ${ }^{1}$, Renáta Kissová ${ }^{1}$, Cyril Klement $^{1}$, Hana Blaškovičová ${ }^{2}$, Branko Takáč ${ }^{3}$, \\ Svetozár Dluholucký ${ }^{3}$ \\ ${ }^{1}$ Regional Authority of Public Health Banská Bystrica, Division of Medical Microbiology, Banská Bystrica, Slovak Republic \\ ${ }^{2}$ Authority of Public Health, National Reference Center for Influenza, Bratislava, Slovak Republic \\ ${ }^{3}$ Children Faculty Hospital Banská Bystrica, Banská Bystrica, Slovak Republic
}

\begin{abstract}
SUMMARY
Many severe diseases of the respiratory tract lead to hospitalisation. These diseases are often caused by viral infections and may cause increased mortality. The most common viral pathogens involved in these cases, which are also associated with significant morbidity and mortality during the influenza seasons are influenza viruses. Rapid differential diagnosis of influenza viruses is therefore of great importance. Classical diagnosis of these viruses involves virus cultures. Of the rapid diagnostic methodologies which have been developed are RT-PCR, multiplex PCR, real-time PCR. In the present study we have monitored clinical samples from patients of different age groups from selected regions in Slovakia and compared the effectiveness of the classical and molecular biological diagnostic methods. The molecular biological methods proved to be rapid, accurate and effective. Application of these techniques in diagnosis of the respiratory illnesses should help in the prevention, therapy and disease control.
\end{abstract}

Key words: influenza viruses, diagnostic choices, cultivation, RT-PCR, real-time PCR, effectiveness of diagnosis

Address for correspondence: L. Mad'arová, Regional Authority of Public Health Banská Bystrica, Division of Medical Microbiology, Cesta k nemocnici 25, 97556 Banská Bystrica, Slovak Republic. E-mail: lucia.madarova@vzbb.sk

\section{INTRODUCTION}

Human influenza is a highly contagious acute respiratory tract disease, which can cause severe morbidity and mortality, particularly in elderly or immuno-compromised patients (1). Three distinct immunological types of influenza viruses have been described on the basis of antigenic differences in the matrix (M) protein and the nucleoprotein. Beside other differences influenza viruses $\mathrm{A}$ and $\mathrm{B}$ are asociated with seasonal morbidity and mortality, while influenza $\mathrm{C}$ causes mild upper respiratory tract infections in children and adolescents $(2,3)$. Influenza virus A is further classified into different subtypes according to antigenic and genetic differences in its surface glycoproteins, hemagglutinin (HA) and neuraminidase (NA). Fifteen HA subtypes and 9 NA subtypes have been identified to date. Until recently, only H1N1, $\mathrm{H} 2 \mathrm{~N} 2$, and $\mathrm{H} 3 \mathrm{~N} 2$ subtypes have been associated with widespread epidemics in humans. Influenza virus A subtype H1N2 emerged and caused respiratory infections in patients from Israel and other countries during the 2001-2002 influenza season $(4,5,6)$. The antigenic variability of influenza $A$ arises as a result of antigenic shift and antigenic drift. Rate of mutation in the influenza virus genome is very high $(7,8)$.
Influenza infections occur in well expressed seasonal patterns. They are a cause of serious worry as serious medical conditions and complications such as debilitating febrile illness lasting for 1-2 weeks can occur in healthy young adults, in patients with pre-existing respiratory or cardio-vascular disease, and in the frail elderly persons. One characteristic of seasonal influenza activity is that it leads to excess or hidden deaths. These deaths are not usually attributed to influenza virus infection but caused either by viral or bacterial pneumonia, secondary to influenza infection (7).

Rapid diagnosis of influenza infections is important for surveillance, prevention and therapy. Traditional method (gold diagnostic standard) for diagnosis of influenza virus infections, is egg inoculation where the virus replicates in the amniotic fluid. Egg inoculation is not practical in all diagnostic laboratories; the method is still used for producing current vaccines, because egg cultivation remains the best method of quickly generating very high titres of virus (22). In diagnostic laboratories, usually the tissue cultures isolation methods are applied. The commonly used cell lines are primary rhesus monkey kidney, cynomolgus monkey kidney, or Madin-Darby canine kidney (MDCK). Virus is detected by examining the cells for cytopathic effect (CPE) and 
expression of viral hemagglutinin on the surface of infected cells. Viral hemagglutinin is detected by adding a suspension of guinea pig erythrocytes to the culture and examining it for adsorption of the erythrocytes to the surface of the cells in culture (hemadsorption). The advantage of virus culturing is its sensitivity, but the main disadvantage is that the CPE or HA expression usually takes 2-3 days to develop, interpretation of results may take as long as 7 to 10 days $(4,22-24)$. Although traditional culturing method is one of the most sensitive methods for the detection of virus, it often does not provide results in a time frame that is clinically relevant. The antiviral therapy is only effective when given in the first 48 hours after the onset of symptoms, for this reason a shell vial culture method was developed. The rapid culture methods have been shown to be $60 \%$ to $100 \%$ sensitive in detecting influenza virus relative to traditional culture methods (25-27). The main drawback of this method is the increased level of expertise required for performing and interpreting these types of cultures.

Detecting increase in antibody titers in paired acute and convalescent sera (collected 3 to 4 weeks apart) can be a useful tool for diagnosing infections, but this method is usually applied only when other attempts of diagnosis fail. Traditional serologically assays are complement fixation test and hemagglutinin inhibition. Serological assays for diagnostic or epidemiologic purposes do not fit into the routine of most clinical laboratories but these assays are often reserved for large reference centres or public health laboratories (22).

Microscopic techniques apply fluorescent labeled antibodies for detection of the virus on slide specimens. Although this method is useful, it is less sensitive $(22,28-32)$.

Viral antigen can be also detected in clinical specimens using commercial enzyme immunoassay devices. The best known are Directigen ${ }^{\circledR}$ Flu A (Directigen ${ }^{\circledR}$ Flu A+B) (Becton-Dickinson, Cockeysville, Maryland), FLU OIA ${ }^{\circledR}$ (Biostar, Boulder, Colorado) and ZstatFlu ${ }^{\circledR}$ (ZymeTx, Oklahoma City, Oklahoma) (22). These devices vary regarding the time required for performance of the test (15-45 minutes), the virus types detected (influenza A only or both influenza A and B), test format structure, and the specimens recommended for testing (22). Directigen ${ }^{\circledR}$ Flu A from Becton-Dickinson, (Cockeysville, Maryland) is the most widely used antigen detection device and also the most comprehensively evaluated in the literature (22). Directigen ${ }^{\circledR}$ reports sensitivities ranging from $41 \%$ to $100 \%$ and specificities of $71 \%$ to $100 \%$, depending on the type of specimen collected, conditions during sample collection, and patient populations studied (22, 28, 30, 33-36).

Rapid and sensitive molecular diagnostic techniques for the detection of influenza viruses have been developed and evaluated. Conventional RT-PCR is one of the best-known methods $(4,37$, $38,39)$. In the so-called „multiplex“ format, PCR assays have been designed to amplify more than one respiratory viral target in the same PCR test (31, 40-45).

Real-time RT-PCRs and multiplex real-time PCRs for the detection of influenza viruses in clinical samples have recently been described (44, 46-49). Commercial real-time PCR instruments that have recently become available include the ABI PRISM 5700 a 7700 (Applied Biosystems, Foster City, CA), iCycler (BioRad, Hercules, CA), LightCycler instrument (Roche Molecular Biochemicals, Indianapolis, IN), SmartCycler (Cepheid, Sunnyvale, CA), MX4000 (Strategene, La Jolla, CA) a Roto-Gene (Corbett
Research, Sydney, Australia) (50). Probe detection formats, which have been most frequently adapted to real-time instruments, include TaqMan (Roche Diagnostics Corporation), Molecular beacons and FRET (Fluorescent Resonance Energy Transfer, Roche Molecular Biochemicals) (50).

Symptoms and signs of influenza may be similar to other types of respiratory illnesses, prompt diagnosis of influenza infection would therefore facilitate effective patient management, public health and vaccination programs as well as appropriate use of antiviral therapy $(9,18-21)$. Considering the importance of rapid diagnosis, we have compared the classical viral culture method and modern molecular methods such as RT-PCR and real-time PCR for diagnosing influenza viruses and other infectious agents during the influenza season in patients with respiratory illnesses.

\section{MATERIAL AND METHODS}

\section{Sample Collection}

Clinical samples such as nasopharyngeal swabs and postmortem material, or other biological material from patients were taken by sentinel and nonsentinel physicians (Children Faculty Hospital Banská Bystrica, Department of Pneumology; Health Care Surveillance Authority, Medico-Judicial and Pathologicalanatomical Workplace Banská Bystrica) from central Slovakia region (region of Banská Bystrica and region of Žilina). Patients included both adult and pediatric patients from sentinel and nonsentinel physicians from central Slovakia region. Nasopharyngeal swabs were collected and placed into containers with viral transport medium (Medium 199 with 0,5\% BSA and antibiotics Penicillin G, Streptomycin and Amphotericin) (WHO 2002) supplied by the laboratory.

These samples were then delivered for analysis to Regional Authority of Public Health Banská Bystrica, Division of Medical Microbiology, Departments of Molecular Biology and Medical Virology. We monitored the presence of influenza viruses by cultivation and PCR methods. Furthermore, differential diagnosis of influenza virus employing PCR and real-time PCR methods was done.

\section{Viral Culture}

Viral cultures were carried out in accordance with standard virological techniques and WHO protocol.

Tissue culture isolations: Specimens were inoculated into culture monolayers of Madin-Darby canine kidney (MDCK) cells and into 8-10 days old chicken embryos and passaged at least three times in these cells or chicken embryos before reporting inability to recover virus from the specimen.

MDCK cells were maintained in D-MEM medium with L-glutamine containing 0,2\% bovine serum albumin, HEPES buffer, $10 \%$ fetal bovine serum and antibiotics at $37{ }^{\circ} \mathrm{C}$ in $5 \%$ $\mathrm{CO}_{2}$. Cells were replaced after a maximum of 15 sequential passages. Infected monolayers of cells were maintained in the same D-MEM medium, but with TPCK-trypsin and without fetal bovine serum at $34{ }^{\circ} \mathrm{C}$ in $5 \% \mathrm{CO}_{2}$. Cells were monitored for cytopathic effect (CPE) and observed daily under a light microscope at 40x magnification. Passages were maintained at least 7 days and stopped if $3+$ or $4+\mathrm{CPE}$ was observed. Every second day 
a hemagglutination test was performed. We used three kinds of red blood cells - chicken ( $0,5 \%$ suspension), guinea pig and human type 0 (both $0,75 \%$ suspension).

Inoculated 8-10 day's embryonated chicken embryos were incubated at $34{ }^{\circ} \mathrm{C}$ for $2-3$ days. A hemagglutination test with three kinds of red blood cells was performed with harvested fluids. Uninoculated residual specimens were stored at $-70{ }^{\circ} \mathrm{C}$.

\section{Isolation of Viral RNA from Samples}

Viral RNA was isolated from clinical samples using the commercial kit (Viral Nucleic Acid Isolation Kit, Roche Diagnostics 2002), the mannufacturer's protocol was followed. To each series of nucleic acid isolation a sample of deionized water was integrated. This sample was used as a negative control for nucleic acid isolation.

\section{Detection of Influenza Viral RNA Using PCR}

For detection of influenza RNA in biological material samples we used a conventional RT-PCR method. Diagnostic sets GenePak ${ }^{\circledR}$ RNA PCR TEST InfluenzaA and GenePak ${ }^{\circledR}$ RNA PCR TEST InfluenzaB from GENTECH (Moscow) were used. Reactions of reverse transcription and PCR were made separately under different conditions of reaction (GENTECH, 2005). Reverse transcription conditions: $25{ }^{\circ} \mathrm{C} / 10$ minutes, $40{ }^{\circ} \mathrm{C} / 30$ minutes, $50{ }^{\circ} \mathrm{C} / 10$ minutes. After the addition of STOP solution: incubation at $80{ }^{\circ} \mathrm{C} / 15$ minutes.

PCR conditions: Denaturation: $95{ }^{\circ} \mathrm{C} / 2$ minutes. Amplification: 45 cycles $95{ }^{\circ} \mathrm{C} / 20$ seconds, $58{ }^{\circ} \mathrm{C} / 20$ seconds, $74{ }^{\circ} \mathrm{C} /$ 40 seconds; $74{ }^{\circ} \mathrm{C} / 2$ minutes. We used Hybaid PCR express thermal cycler@ Hybaid Limited for RT-PCR.

Control of reaction: At the same time and under the same conditions, the control of procedure of RT-PCR was inspected using the positive (RNA of influenza A or B virus) and the negative control (deionized water) of reaction, which are included in the Diagnostic Kit.

Electrophoresis: After the completion of amplification in thermocycler, the PCR products were analysed with UV light after electrophoresis in agarose gel ( $90 \mathrm{~V} / 1$ hour; $120 \mathrm{~V} / 2$ hours).

Differential diagnosis of influenza: Apart from influenza viruses diagnosis we also tried a differential diagnosis of influenza viruses. Presence of other viral agents such as parainfluenza virus, RSV-respiratory syncytial virus, adenovirus, human metapneumovirus, and bacterial respiratory agents such as Streptococcus pneumoniae, Chlamydia pneumoniae, Mycoplasma pneumoniae, Pneumocystis carinii, Bordetella pertussis and Bordetella parapertussis was inspected.

Conventional PCR was applied for the diagnosis of adenovirus, Streptococcus pneumoniae, Chlamydia pneumoniae, Mycoplasma pneumoniae, Pneumocystis carinii), RT-PCR (parainfluenza virus, $\mathrm{RSV}$, human metapneumovirus and the real-time PCR for the diagnosis of Bordetella pertussis and Bordetella parapertussis.

External quality assessment: The assessment was done at the Departments of Medical Virology and Molecular Biology, Division of Medical Microbiology, Regional Authority of Public Health, execute laboratory practice in accordance with STN ISO EN/IEC 17 025:2005. This work place attends on international quality assurance.

In addition during October 2007 Regional Authority of Public Health, Division of Medical Microbiology, Departments of
Medical Virology and Molecular Biology, attended on external quality assurance last time. This quality control assurance was organized by National Reference Centre for Influenza laboratory in Bratislava. Both departments were 100\% successful.

The diagnostic sets [GenePak® RNA PCR TEST InfluenzaA and GenePak ${ }^{\circledR}$ RNA PCR TEST InfluenzaB, GENTECH (Moscow)] were tested using reference materials provided by National Reference Centre for Influenza laboratory.

\section{RESULTS}

In 2005/2006 influenza season 229 biological samples were examined in department of Medical Virology, Division of Medical Microbiology, Regional Authority of Public Health Banská Bystrica. Virus isolation was made by cultivation on MDCK tissue cultures and chicken embryos. The presence of influenza virus was detected in 13 cases. All strains were detected on MDCK tissue cultures and one of them was also detected on chicken embryo. All 13 positive samples were delivered to the laboratory of the National Reference Centre for Influenza (Authority of Public Health of Slovak republic in Bratislava) for typing. The strains were typed as influenza B/Malaysia/2506/2004-like (12 samples) or like influenza A/H3N2/California/07/04-like (1 sample).

In 2006/2007 influenza season 176 nasopharyngeal swabs were examined in Department of Medical Virology, Division of Medical Microbiology, Regional Authority of Public Health Banská Bystrica. The presence of influenza virus in examined samples was detected in 3 cases. All strains were detected on MDCK tissue cultures and two of them were also detected on chicken embryos. All 3 positive samples were delivered to the National Reference Centre for Influenza laboratory in Bratislava for typing. The strains were typed as influenza A/Wisconsin/67/2005-like. The results from 2005/2006 and 2006/2007 seasons are summarized in Tables 1 and 2.

Table 1. Diagnosis of influenza in 2005/2006 influenza season by tissue culture and embryo cultivation methods

\begin{tabular}{|l|c|c|}
\hline 01. 09. 2005-31. 05.2006 \\
\hline Examination & $\begin{array}{c}\text { Cultivation on MDCK } \\
\text { tissue cultures }\end{array}$ & $\begin{array}{c}\text { Cultivation on chicken } \\
\text { embryos }\end{array}$ \\
\hline All samples & 229 & 229 \\
\hline Positive samples & 13 & 1 \\
\hline
\end{tabular}

Table 2. Diagnosis of influenza in 2006/2007 influenza season by tissue culture and embryo cultivation methods

\begin{tabular}{|l|c|c|}
\hline 01. 09. 2006 - 31. 05. 2007 \\
\hline Examination & $\begin{array}{c}\text { Cultivation on MDCK } \\
\text { tissue cultures }\end{array}$ & $\begin{array}{c}\text { Cultivation on chicken } \\
\text { embryos }\end{array}$ \\
\hline All samples & 176 & 176 \\
\hline Positive samples & 3 & 2 \\
\hline
\end{tabular}


In the 2005/2006 influenza season 78 biological materials were examined for the presence of different infectious agents causing respiratory tract infections by RT-PCR in department of Molecular Biology, Division of Medical Microbiology, Regional Authority of Public Health Banská Bystrica. The presence of influenza A virus was tested in 74 samples and the presence of influenza $B$ virus was tested in all 78 samples. The presence of influenza $A$ virus was detected in 3 cases. The presence of influenza $B$ virus was detected in 7 cases. Differential diagnosis of influenza was performed in the same time, too. Samples were tested for the presence of influenza A-H5, H7, Pneumocystis carinii, Mycoplasma pneumoniae, adenovirus, parainfluenzavirus, respiratory syncytial virus (RSV), Bordetella pertussis and Bordetella parapertussis. Results of diagnosis and differential diagnosis of influenza viruses, in 2005/2006 influenza season, by molecular biology methods are summarized in Table 3.

In 2006/2007 influenza season 99 biological samples were examined for the presence of respiratory tract infection agents by RT-PCR in department of Molecular Biology, Division of Medical Microbiology, Regional Authority of Public Health Banská Bystrica. The presence of influenza A virus was tested in 171 samples and the presence of influenza B virus was tested in 157 samples. The presence of influenza A virus was detected in 13 cases. The presence of influenza B virus was detected in 1 case. Differential diagnosis of influenza was performed in the same time, too. The samples were tested for the presence of influenza A-H5, H7, Pneumocystis carinii, Mycoplasma pneumoniae, adenovirus, parainfluenzavirus, respiratory syncytial virus (RSV), Bordetella pertussis, Bordetella parapertussis, Chlamydia pneumoniae, human metapneumovirus (HMPV), Streptococcus pneumoniae. Results of diagnosis and differential diagnosis of influenza viruses, in 2006/2007 influenza season, by molecular biological methods are summarized in Table 4.
In 2005/2006 and 2006/2007 influenza seasons in total 217 biological samples were examined both by cultivation on MDCK tissue cultures and by RT-PCR. Four samples were positive by cultivation on MDCK tissue cultures. At the National Reference Centre for Influenza these cases were typed as subtype of influenza A/Wisconsin/67/2005-like in one case, and as influenza B/ Malaysia/2506/2004-like in three cases. By molecular biological method, RT-PCR, the presence of influenza virus was detected in 20 cases. In fourteen positive cases influenza A strains and in 6 influenza B virus were detected. Results of parallel testing are summarized in Table 5.

\section{DISCUSSION AND CONCLUSIONS}

Surveillance for influenza viruses in population is important for providing information concerning the presence of the influenza virus subtypes circulating in the population. This information is useful in vaccine development and for timely beginning of antiviral therapy, too $(4,9,10)$.

Vaccination is the best choice for prevention of the illness. The targeted population includes high risk patients due to comorbidity, all patients aged over 65 years, children and immuno-compromised individuals (11).

Antiviral drugs can be used for prophylaxis of unvaccinated persons who are exposed to influenza, and for treatment of both vaccinated and unvaccinated patients who develop typical symptoms. Prophylaxis with an antiviral drug may be useful for the unvaccinated people or if circulating strains prove to be different from vaccine strains (reviewed in 12, 13, 14, 17).

We tested in total 217 biological samples during the 2005/2006 and 2006/2007 influenza seasons. Samples were processed and virus culture methods, RT-PCR and real-time PCR were used for

Table 3. Differential diagnosis of influenza during 2005/2006 influenza season using molecular-biology methods

\begin{tabular}{|c|c|c|c|c|c|c|c|c|c|}
\hline \multicolumn{10}{|c|}{ 01. 09. $2005-31.05 .2006$} \\
\hline Examination & $I A^{*}$ & $\mathrm{IB}^{*}$ & $\mathrm{~A}-\mathrm{H} 5, \mathrm{H} 7$ & $P C^{*}$ & $\mathrm{MP}^{*}$ & $A V^{*}$ & $\mathrm{Pl}^{*}$ & $\mathrm{RSV}^{*}$ & $\mathrm{BP}+\mathrm{BPara*}$ \\
\hline All samples & 74 & 78 & 7 & 20 & 57 & 50 & 54 & 64 & 21 \\
\hline Positive samples & 3 & 7 & 0 & 2 & 0 & 0 & 0 & 1 & 0 \\
\hline
\end{tabular}

*For explanation see Table 4.

Table 4. Differential diagnosis of influenza during 2006/2007 influenza season using molecular-biological methods

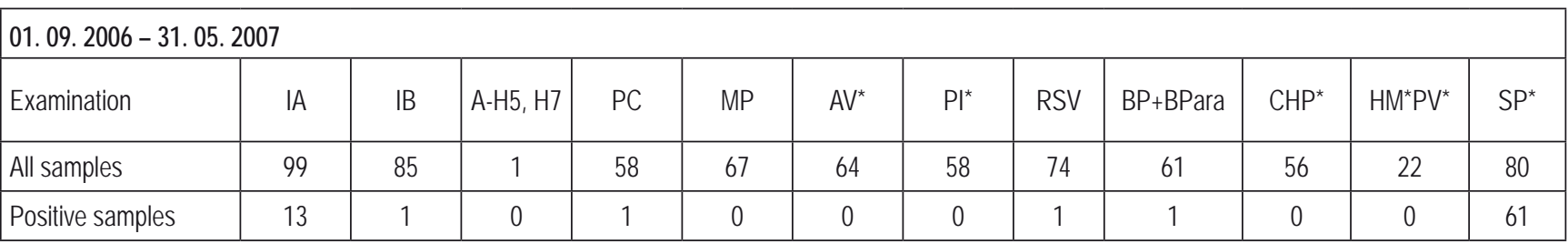

*Abbreviations used:

IA:Influenza A

IB: Influenza B

A- H5, H7: Influenza A, subtypes H5, H7

PC: Pneumocystis carinii

MP: Mycoplasma pneumoniae
PI: Parainfluenza

BP: Bordetella pertussis

RSV: Respiration syncytial virus

CHP: Chlamydia pneumoniae

HMPV: Human metapneumovírus
SP: Sterptococcus pneumoniae

AV: Adenovirus

Bpara: Bordetella parapertussis 
Table 5. Comparison of classical cultivation method and molecular-biological methods for diagnosis of influenza in $2005 / 2006$ and 2006/2007 influenza seasons

\begin{tabular}{|c|c|c|c|c|c|c|}
\hline & \multicolumn{3}{|c|}{ Influenza season 2005/2006 } & \multicolumn{3}{|c|}{ Influenza season 2006/2007 } \\
\hline & \multirow{2}{*}{ Cultivation } & \multicolumn{2}{|c|}{ RT-PCR } & \multirow{2}{*}{ Cultivation } & \multicolumn{2}{|c|}{ RT-PCR } \\
\hline & & Influenza A & Influenza B & & Influenza A & Influenza B \\
\hline All samples & 64 & 64 & 64 & 153 & 153 & 153 \\
\hline Positive samples & 1 & 3 & 6 & 3 & 11 & 0 \\
\hline \multicolumn{7}{|l|}{ Total } \\
\hline & & \multirow{2}{*}{\multicolumn{2}{|c|}{ Cultivation }} & \multicolumn{3}{|c|}{ RT-PCR } \\
\hline & & & & \multicolumn{3}{|c|}{ Influenza A + Influenza B } \\
\hline \multicolumn{2}{|c|}{ All samples in both seasons } & \multicolumn{2}{|c|}{217} & \multicolumn{3}{|c|}{217} \\
\hline \multicolumn{2}{|l|}{ Positive samples } & \multicolumn{2}{|c|}{4} & \multicolumn{3}{|c|}{$14+6$} \\
\hline
\end{tabular}

diagnosis. Differential diagnosis was done in selected samples.

Our findings show that all samples positive for cultivation and majority of PCR positive samples were detected during the 2005/2006 influenza season in which the epidemic lasted from the 7 th till the 15 th week with the peak in the 13th week, except the two samples diagnosed in December and in January respectively.

During 2006/2007 influenza season the epidemic lasted from the 2nd till the 8th week with the peak in the 5th-6th week. All cultivation positive samples and majority of PCR positive samples were detected during this period, except of two samples diagnosed in January and in March respectively.

Comparing cultivation and RT-PCR methods for detection of influenza viruses in biological material samples show us some differences (Table 5). Reasons for these differences might be bad and delay in sample collection, or the delay in delivery of samples to the laboratory or low titer of influenza virus and low virulence in the beginning of the influenza season. In these cases the possibility of detecting the presence of virus by cultivation rapidly decreased. By RT-PCR even small quantities can be detected, so extremely low titers do not pose a problem, but degradation of RNA by enzymes such as RNAse, in the body fluids do pose a problem which can be lowered by strict storing conditions.

High positivity was recorded in samples which were tested for the presence of Streptococcus pneumoniae when trying for differential diagnosis of influenza viruses. These results relate with the study of Streptococcus pneumoniae prevalence in children attending schools, child care groups and nurseries. A study was carried out to evaluate availability and effectiveness of vaccination against Streptococcus pneumoniae.

In conclusion both, conventional RT-PCR and real-time PCR are the useful tools for speeding up the diagnosis and differential diagnosis of influenza viruses. Both methods are very rapid, sensitive and specific. The total time required for processing of samples and evaluating of results reduced from 2-10 days for cultivation to a few hours by PCR. These techniques are efficient tools for effective diagnosis of influenza virus, efficient tools for preventing epidemics and misuse of antibiotics.

\section{Acknowledgements}

We thank RNDr. Shubhada Bopegamage, CSc., of the Slovak Medical University for the final remarks and suggestions.

\section{REFERENCES}

1. Glezen WP. Serious morbidity and mortality associated with influenza epidemics. Epidemiol Rev. 1982;4:25-44.

2. Monto AS, Ohmit SE, Margulies JR, Talsma A. Medical practice-based influenza surveillace: viral prevalence and assessment of morbidity. Am J Epidemiol. 1995 Mar 15;141(6):502-6.

3. Moriuchi H, Katsushima N, Nishimura H, Nakamura K, Numazaki Y. Community-acquired influenza $\mathrm{C}$ virus infection in children. J Pediatr. 1991 Feb;118(2):235-8.

4. Hindiyeh M, Levy V, Azar R, Varsano N, Regev L, Shalev Y, et al. Evaluation of a multiplex real-time reverse transcriptase PCR assay for detection and differentiation of influenza viruses A and B during the 2001-2002 influenza season in Israel. J Clin Microbiol. 2005 Feb;43(2):589-95.

5. Gregory V, Bennett M, Orkhan MH, Al-Hajjar S, Varsano N, Mendelson E, et al. Emergence of influenza A H1N2 reassortant viruses in the human population during 2001. Virology. 2002 Aug 15;300(1):1-7.

6. Guo YJ, Xu XY, Cox NJ. Human influenza A (H1N2) viruses isolated from China. J Gen Virol. 1992 Feb;73(Pt 2):383-7.

7. Zambon MC. Epidemiology and pathogenesis of influenza. J Antimicrob Chemother. 1999 Nov;44 Suppl B:3-9.

8. Stephenson I, Zambon M. The epidemiology of influenza. Occup Med (Lond). 2002 Aug;52(5):241-7.

9. Polanecký V, Tůmová B. A proposal of action plan for pandemic influenza caused by a new virus variant--the National Pandemic Plan of the Czech Republic (NPP-CR). Cent Eur J Public Health. 2001 Nov;9(4):A-H.

10. Avian influenza. Cent Eur J Public Health. 2006 Mar;14(1):47-50.

11. Fleming DM. Influenza diagnosis and treatment: a view from clinical practice. Philos Trans R Soc Lond B Biol Sci. 2001 Dec 29;356(1416):193343.

12. American College of Obstetricians and Gynecologists. Antiviral drugs for prophylaxis and treatment of influenza. Obstet Gynecol. 2005 Feb;105(2):427-9.

13. Stiver G. The treatment of influenza with antiviral drugs. CMAJ. 2003 Jan 7;168(1):49-56.

14. Hayden FG. Perspectives on antiviral use during pandemic influenza. Philos Trans R Soc Lond B Biol Sci. 2001 Dec 29;356(1416):1877-84.

15. Hayden FG, Belshe R, Villanueva C, Lanno R, Hughes C, Small I, et al. Management of influenza in households: a prospective, randomized comparison of oseltamivir treatment with or without postexposure prophylaxis. J Infect Dis. 2004 Feb 1;189(3): 440-9. 
16. Oxford J, Balasingam S, Lambkin R. A new millennium conundrum: how to use a powerful class of influenza anti-neuraminidase drugs (NAIs) in the community. J Antimicrob Chemother. 2004 Feb;53(2):133-6.

17. Williamson JC, Pegram PS. Neuraminidase inhibitors in patients with underlying airways disease. Am J Respir Med. 2002;1(2):85-90.

18. Stone B, Burrows J, Schepetiuk S, Higgins G, Hampson A, Shaw R, et al. Rapid detection and simultaneous subtype differentiation of influenza A viruses by real time PCR. J Virol Methods. 2004 May;117(2):10312 .

19. Hayden FG, Osterhaus AD, Treanor JJ, Fleming DM, Aoki FY, Nicholson KG, et al; GG167 Influenza Study Group. Efficacy and safety of neuraminidase inhibitor zanamivir in the treatment of influenza virus infections. N Engl J Med. 1997 Sep 25;337(13):874-80.

20. Mäkelä MJ, Pauksens K, Rostila T, Fleming DM, Man CY, Keene ON, et al. Clinical efficacy and safety of the orally inhaled neuraminidase inhibitor zanamivir in the treatment of influenza: a randomized, double-blind, placebo-controlled European study. J Infect. 2000 Jan;40(1):42-8.

21. Treanor JJ, Hayden FG, Vrooman PS, Barbarash R, Bettis R, Riff D, et al; US Oral Neuraminidase Study Group. Efficacy and safety of the oral neuraminidase inhibitor oseltamivir treating acute influenza: a randomized controlled trial. JAMA. 2000 Feb 23;283(8):1016-24.

22. Newton DW, Treanor JJ, Menegus MA. Clinical and laboratory diagnosis of influenza virus infections. Am J Manag Care. 2000 Mar;6(5 Suppl): S265-75.

23. Ziegler T, Cox NJ. Influenza viruses. In: Murray PR, Baron EJ, Pfaller MA, Tenover FC, Yolken RH, editors. Manual of clinical microbiology. Washington, D.C.: American Society for Microbiology; 1999. p. 92835 .

24. Chomel JJ, Remilleux MF, Marchand P, Aymard M. Rapid diagnosis of influenza A. Comparison with ELISA immunocapture and culture. J Virol Methods. 1992 Jun;37(3):337-43.

25. Espy MJ, Smith TF, Harmon MW, Kendal AP. Rapid detection of influenza virus by shell vial assay with monoclonal antibodies. J Clin Microbiol. 1986 Oct;24(4):677-9.

26. Mills RD, Cain KJ, Woods GL. Detection of influenza virus by centrifugal inoculation of MDCK cells and staining with monoclonal antibodies. J Clin Microbiol. 1989 Nov;27(11):2505-8.

27. Stokes CE, Bernstein JM, Kyger SA, Hayden FG. Rapid diagnosis of influenza A and B by 24-h fluorescent focus assay. J Clin Microbiol. 1988 Jul;26(7):1263-6.

28. Dominguez EA, Taber LH, Couch RB. Comparison of rapid diagnostic techniques for respiratory syncytial and influenza A virus respiratory infections in young children. J Clin Microbiol. 1993 Sep;31(9):2286-90.

29. Atmar RL, Baxter BD, Dominguez EA, Taber LH. Comparison of reverse transcription- PCR with tissue culture and other rapid diagnostic assays for detection of type A influenza virus. J Clin Microbiol. 1996 Oct;34(10):2604-6

30. Reina J, Munar M, Blanco I. Evaluation of a direct immunofluorescence assay, dot-blot enzyme immunoassay, and shell vial culture in diagnosis of lower respiratory tract infections caused by influenza A virus. Diagn Microbiol Infect Dis. 1996 Jul;25(3):143-5.

31. Ellis JS, Fleming DM, Zambon MC. Multiplex reverse transcription-PCR for surveillance of influenza A and B viruses in England and Wales in 1995 and 1996. J Clin Microbiol. 1997 Aug;35(8):2076-82.

32. Stockton J, Ellis JS, Saville M, Clewley JP, Zambon MC. Multiplex PCR for typing and subtyping influenza and respiratory syncytial viruses. J Clin Microbiol. 1998 Oct;36(10):2990-5.

33. Waner JL, Todd SJ, Shalaby H, Murphy P, Wall LV. Comparison of Directigen FLU- A with viral isolation and direct immunofluorescence for the rapid detection and identification of influenza A virus. J Clin Microbiol. 1991 Mar;29(3):479-82.

34. Ryan-Poirier KA, Katz JM, Webster RG, Kawaoka Y. Application of Directigen FLU-A for the detection of influenza A virus in human and nonhuman specimens. J Clin Microbiol. 1992 May;30(5):1072-5.
35. Marcante R, Chiumento F, Palů G, Cavedon G. Rapid diagnosis of influenza type A infection: comparison of shell-vial culture, Directigen FLU-A and enzyme-linked immunosorbent assay. New Microbiol. 1996 Apr;19(2):141-7.

36. Booth S, Baleriola C, Rawlinson WD. Comparison of two rapid influenza $\mathrm{A} / \mathrm{B}$ test kits with reference methods showing high specificity and sensitivity for influenza A infection. J Med Virol. 2006 May;78(5):619-22.

37. Fouchier RA, Bestebroer TM, Herfst S, Van Der Kemp L, Rimmelzwaan GF, Osterhaus AD. Detection of influenza A viruses from different species by PCR amplification of conserved sequences in the matrix gene. J Clin Microbiol. 2000 Nov;38(11):4096-101.

38. Hindiyeh M, Hillyard DR, Carroll KC. Evaluation of the Prodesse Hexaplex multiplex PCR assay for direct detection of seven respiratory viruses in clinical specimens. Am J Clin Pathol. 2001 Aug;116(2):218-24.

39. Poddar SK. Influenza virus types and subtypes detection by single step single tube multiplex reverse transcription-polymerase chain reaction (RT-PCR) and agarose gel electrophoresis. J Virol Methods. 2002 Jan;99(1-2):63-70

40. Fan J, Henrickson KJ, Savatski LL. Rapid simultaneous diagnosis of infections with respiratory syncytial viruses $A$ and $B$, influenza viruses $\mathrm{A}$ and $\mathrm{B}$, and human parainfluenza virus types 1,2 and 3 by multiplex quantitative reverse transcription-polymerase chain reaction-enzyme hybridization assay (Hexaplex). Clin Infect Dis. 1998 Jun;26(6):1397402

41. Gröndahl B, Puppe W, Hoppe A, Kühne I, Weigl JA, Schmitt HJ. Rapid identification of nine microorganisms causing acute respiratory tract infections by single-tube multiplex reverse transcription-PCR: feasibility study. J Clin Microbiol. 1999 Jan;37(1):1-7.

42. Liolios L, Jenney A, Spelman D, Kotsimbos T, Catton M, Wesselingh S. Comparison of a multiplex reverse transcription-PCR-enzyme hybridization assay with conventional viral culture and immunofluorescence techniques for the detection of seven viral respiratory pathogens. J Clin Microbiol. 2001 Aug;39(8):2779-83.

43. Kehl SC, Henrickson KJ, Hua W, Fan J. Evaluation of the Hexaplex assay for detection of respiratory viruses in children. J Clin Microbiol. 2001 May;39(5):1696-701.

44. Boivin G, Côté S, Déry P, De Serres G, Bergeron MG. Multiplex real-time PCR assay for detection of influenza and human respiratory syncytial viruses. J Clin Microbiol. 2004 Jan;42(1):45-51.

45. Edwards MC, Gibbs RA. Multiplex PCR: advantages, development, and applications. PCR Methods Appl. 1994 Feb;3(4):S65-75.

46. Habib-Bein NF, Beckwith WH 3rd, Mayo D, Landry ML. Comparison of SmartCycler real-time reverse transcription-PCR assay in a public health laboratory with direct immunofluorescence and cell culture assays in a medical center for detection of influenza A virus. J Clin Microbiol. 2003 Aug;41(8):3597-601.

47. Schweiger B, Zadow I, Heckler R, Timm H, Pauli G. Application of a fluorogenic PCR assay for typing and subtyping of influenza viruses in respiratory samples. J Clin Microbiol. 2000 Apr;38(4):1552-8.

48. Smith AB, Mock V, Melear R, Colarusso P, Willis DE. Rapid detection of influenza $A$ and $B$ viruses in clinical specimens by Light Cycler real-time RT-PCR. J Clin Virol. 2003 Sep;28(1):51-8.

49. Van Elden LJ, Nijhuis M, Schipper P, Schuurman R, van Loon AM. Simultaneous detection of influenza viruses A and B using real-time quantitative PCR. J Clin Microbiol. 2001 Jan;39(1):196-200.

50. Reischl U, Cockerill F, Wittwer C, editors. Rapid cycle real-time PCRmethods and applications: microbiology and food analysis. Berlin: Springer-Verlag; 2002. 